\title{
Article
}

\section{Responding to the health needs of trafficked people: A qualitative study of professionals in England and Scotland}

\author{
Williamson, Victoria, Borschmann, Rohan, Zimmerman, Cathy, \\ Howard, Louise M., Stanley, Nicky and Oram, Sian \\ Available at http://clok.uclan.ac.uk/29784/ \\ Williamson, Victoria, Borschmann, Rohan, Zimmerman, Cathy, Howard, Louise \\ M., Stanley, Nicky ORCID: 0000-0002-7644-1625 and Oram, Sian (2020) \\ Responding to the health needs of trafficked people: A qualitative study of \\ professionals in England and Scotland. Health \& Social Care in the \\ Community, 28 (1). pp. 173-181. ISSN 0966-0410
}

It is advisable to refer to the publisher's version if you intend to cite from the work. http://dx.doi.org/10.1111/hsc.12851

For more information about UCLan's research in this area go to http://www.uclan.ac.uk/researchgroups/ and search for <name of research Group>.

For information about Research generally at UCLan please go to http://www.uclan.ac.uk/research/

All outputs in CLoK are protected by Intellectual Property Rights law, including Copyright law. Copyright, IPR and Moral Rights for the works on this site are retained by the individual authors and/or other copyright owners. Terms and conditions for use of this material are defined in the policies page.

\section{CLoK}

Central Lancashire online Knowledge www.clok.uclan.ac.uk

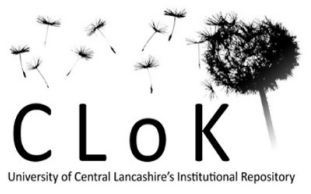




\begin{abstract}
Trafficked people require timely and ongoing access to health services. Yet, many encounter difficulties accessing and utilising healthcare services both while in situations of exploitation and after their escape. This research investigated barriers that hinder healthcare providers from identifying, providing care and making necessary referrals for trafficked people in the United Kingdom. Semi-structured, face-to-face interviews were conducted with healthcare $(n=23)$ and non-health $(\mathrm{n}=27)$ professionals with relevant policy or practical experience related to human trafficking in the UK. Topic guides covered identifying, referring, and providing care to trafficked people. Transcripts were analysed using thematic analysis. Four interconnected themes emerged: trafficked persons' entitlements to healthcare, availability of healthcare resources, providers' knowledge about trafficking, and the particular needs of trafficked individuals. Providers explained that policies limiting entitlements to healthcare created significant obstacles to care, as did the inadequate resourcing of interpreter services, trafficking support services, and specialist mental health services. Few healthcare professionals reported having received training on responses to trafficked people and most were unaware of support options and referral routes. Healthcare professionals will be better equipped to serve trafficked individuals if they are provided training to identify and respond to human trafficking, guidance on referral and support options and entitlements to care. Simultaneously, improving trafficked people's healthcare access and use will also require government interventions to ensure they are not unjustifiably denied health care.
\end{abstract}

Keywords: Trafficking; health services; access; qualitative; healthcare professionals; modern slavery.

\title{
What is known about this topic?
}


- Physical and psychological problems are highly prevalent among trafficked people.

- Access to timely and high-quality healthcare is integral to trafficked people's recovery.

- Trafficking survivors report substantial barriers to healthcare, including restrictions imposed by traffickers, inability to produce documentation to register for care, and inadequate interpreter services.

\section{What this paper adds}

- Policy and system level barriers to timely, high-quality care for trafficked people include inadequate resourcing of interpreter services and specialist mental health services, poor clarity about entitlements to care and options for referral to trafficking support services.

- Training to identify human trafficking and information on referral is likely to benefit healthcare provision.

- Government action is required to ensure trafficked people are not unjustifiably denied medical care. 


\section{Introduction}

Human trafficking, or modern slavery, refers to situations of exploitation where an individual cannot refuse or leave due to threats, coercion or abuse of power (International Labour Organization [ILO], 2017). In 2016, an estimated 40.3 million individuals were victims of modern slavery, including forced labour exploitation, forced sexual exploitation or forced marriage (ILO, 2017). Human trafficking has been associated with physical and psychological abuse, rape, and deprivation of liberty and material needs (Ottisova, Hemmings, Howard, Zimmerman, \& Oram, 2016). Studies conducted with survivors in contact with post-trafficking support services have documented a range of adverse physical (Kiss et al., 2015; Oram et al., 2016; Oram et al., 2012; Ottisova et al., 2016; Turner-Moss, Zimmerman, Howard, \& Oram, 2014; Zimmerman et al., 2008), mental (Abas et al., 2013; Domoney, Howard, Abas, Broadbent, \& Oram, 2015; Oram, Khondoker, Abas, Broadbent, \& Howard, 2015), and sexual and reproductive health problems (Oram, Stöckl, Busza, Howard, \& Zimmerman, 2012; Williams et al., 2010; Zimmerman et al., 2013), including high levels of depression and posttraumatic stress disorder; non-specific symptoms such as headache, fatigue, and back pain; and sexually transmitted infection, including HIV (Zimmerman, Hossain, \& Watts, 2011).

Access to timely, high-quality healthcare is integral to trafficked people's recovery (Baldwin, Eisenman, Sayles, Ryan, \& Chuang, 2011). Healthcare providers can play a critical role in identifying victims of trafficking and making referrals for further support (Viergever, West, Borland, \& Zimmerman, 2015). Yet many victims encounter difficulties accessing appropriate healthcare both during the time they are exploited and after their escape (Westwood et al., 2016). Research conducted with trafficked people in England found that commonly cited barriers to care included restrictions imposed by their traffickers, difficulties providing the identity documents required to register with primary care, and limited availability of interpreters (Westwood et al., 2016). Among the minority that accessed services whilst 
Responding to the health needs of trafficked people

trafficked, most reported being accompanied into consultations by their traffickers, who often interpreted on their behalf (Westwood et al., 2016). Research conducted in the USA similarly found that trafficked people who were able to access healthcare during the time they were being exploited were unable to disclose their experiences of abuse because of language barriers and limited opportunities to speak privately with healthcare professionals (Baldwin et al., 2011). Survey research conducted with healthcare professionals in various settings suggests that many healthcare providers lack the requisite knowledge and confidence to identify and respond appropriately to patients they suspect may have been trafficked (Ross et al., 2015; Viergever et al., 2015). Yet, despite the need for improved health service responses, there is limited evidence from providers about the challenges related to meeting the needs of trafficked people.

This research aimed to identify the factors that hinder and facilitate identification, referral and care for trafficked people in healthcare settings in the United Kingdom (UK). The study explored the experiences of health professionals working in relevant clinical disciplines (e.g. primary care, sexual health, mental health, emergency care, and maternity) and those of other professionals working to help trafficked people access healthcare.

\section{Methods}

\section{Study design}

This was a qualitative study using in-depth interviews. The study was nested within a larger programme of research examining the National Health Service (NHS) response to trafficked people. For example, the research by Westwood et al., (2016) which examined the experiences of trafficked people accessing healthcare.

\section{Sample and setting}

Fifty semi-structured interviews were conducted in England and Scotland in 2017 with health and non-health professionals with relevant policy or practical experience related to human trafficking. Participants were purposively sampled from a range of NHS, central 
Responding to the health needs of trafficked people

government, social care, criminal justice, and voluntary sector organisations based on recommendations from the project steering group and research advisory group, and by employing a snowball sampling methodology. Interviews were conducted in private rooms at each participant's place of employment.

\section{Data collection}

Interviews were conducted by RB and SO. Interview topic guides used for health and non-health professionals contained questions about the same core domains but were tailored according to the interviewee's profession. Interview topics can be found in Table 1. Topic guides were informed by relevant academic literature and the experiential knowledge of the research team, project steering group, and by representatives of trafficking support organisations via the research advisory group. Interviews were digitally recorded and transcribed verbatim by a professional transcription agency. Transcripts were then entered into Nvivo version 10 to facilitate analysis.

\section{Data analysis}

Transcripts were analysed using thematic analysis (Braun \& Clarke, 2006). We utilised the following steps: reading and rereading the transcripts, generating codes, searching for and developing early themes, and revising and classifying themes (Braun \& Clarke,2006). In generating codes, a preliminary coding framework was developed by RB and SO, following independent open coding of a selection of interview transcripts. To ensure rigour, the coding frame was scrutinised by $\mathrm{LMH}, \mathrm{CZ}$, and VW, and developed by VW through further coding and discussion with co-authors before being applied to the remainder of the interview transcripts. A reflexive journal was kept by VW throughout this analysis in an effort to recognize the potential influence of the researcher's prior experiences, beliefs and assumptions, and to prevent premature and/or biased interpretations of the data.

\section{Ethics}


Responding to the health needs of trafficked people

Ethics approval was granted by an independent Research Ethics Committee (Oxfordshire C, reference 08/H0606/71). All study participants were given both oral and written information about the study. Written, informed consent - including consent for the interview to be digitally recorded - was obtained by the interviewer prior to commencing each interview.

\section{Results}

\section{Findings}

Twenty-three participants (46\%) worked for the NHS, encompassing a range of clinical disciplines and grades (see Table 2). Twenty-seven participants (54\%) worked for non-healthsector organisations involved in the care of victims of trafficking including the police and nongovernment organisations (NGO) providing specialist post-trafficking support to trafficked adults and children.

\section{Qualitative findings}

Analysis identified four interconnected themes regarding the barriers to identifying and providing care for/to trafficked people within healthcare settings: entitlements to healthcare, accessing healthcare resources, knowledge of signs of trafficking and trafficked individuals' needs, and addressing barriers to care. These themes were found to be relevant both in accounts of trafficked people's encounters with frontline NHS staff and in discussions of current policy and organisational structures and practices.

\section{Entitlements}

Trafficked people's entitlements to most forms of healthcare and to social and financial support is governed by their immigration status. Participants described how the UK's system of entitlements to such support and the widespread uncertainty about the services trafficked people were able to access free of charge created barriers to care. 
Responding to the health needs of trafficked people

All health professionals interviewed for this research agreed that urgent medical care, including maternity care if required, should be freely provided to trafficked individuals regardless of their immigration status. However, there was uncertainty about trafficked patients' entitlement to non-urgent healthcare and health professionals reported limited understanding about the NHS' obligation to provide individuals with free care.

"Every healthcare Trust is mandated to identify who might be chargeable, and charge them, and take reasonable... reasonable steps to recoup those charges. But nobody says how reasonable is reasonable." (Maternity professional)

Trafficked people were described as having little information about their rights to either chargeable or non-chargeable healthcare, and NGO workers reported that survivors were often misled by traffickers about their entitlement to healthcare:

"The [trafficker] would say, 'No, you're not entitled to, to register with a doctor', particularly if they're undocumented... And I guess the [trafficker's] word becomes gospel if that's the only thing that the person knows." (NGO Representative)

Requirements that prospective patients prove their entitlement to physical and/or mental healthcare were described by several participants as a barrier to care. Interviewees reported that many General Practitioner (GP) practices insisted that prospective patients provide proof of identity and current address in order to register for care, even though this was not required by law: 
Responding to the health needs of trafficked people

"For healthcare, well registering with a GP is generally difficult...many GPs still require photo ID and three utility bills before they are, completely unnecessarily, but before they will register you and that is something which needs to change" (Civil servant).

Trafficked people were frequently unable to provide the documents they needed to register for care with GP practices, as identity documents were often seized by their traffickers. Thus, system-level barriers and the activities of traffickers intersected to impede access to healthcare. In other cases, trafficked individuals who had escaped from their abusers became homeless due to the difficulties associated with accessing housing and other formal support services. These individuals did not have proof of address:

"So, another big issue is often with domestic workers [who] are homeless. People are reluctant to register them because they don't have an address, and I've heard that particularly from mental health services." (Adult NGO)

Entitlement to certain types of healthcare varied by age, creating problems for trafficked adults with limited financial means. Participants working with young people described, for example, that dental care was free for children but chargeable for adults:

“A young person, she had some problem with her teeth... and it wasn't ever really being addressed... And then she turned eighteen and then obviously it was gonna cost her quite a lot. And, um, that was quite frustrating... Sometimes it's quite difficult because [trafficked people] are so limited financially and then they're asked to pay and they can't afford it" (Children's NGO) 
Responding to the health needs of trafficked people

These participants also reported that young people's entitlement to health and other key services were affected by whether they were judged to be a child or an adult, and highlighted that many young people were subject to age dispute proceedings:

"The other one that's a monster with children, is the age assessment...You are assessing someone's age, and that decision influences how they access the rest of the healthcare services, but also the social care system, and also the justice system" (Police)

The broader system of immigration-related entitlements, for example, to social and financial support, also impacted on the provision of healthcare to trafficked people and could cause problems regarding continuity of care. Trafficked people were relocated within the UK during immigration proceedings, disrupting ongoing physical and mental health treatment. Services in one area were not necessarily the same or even available in a different area. If services were successfully accessed following relocation, test results or medical records could be lost or delayed, and trafficking experiences often had to be disclosed again and relationships of trust established with a new clinical team.

"People are moved, they're in temporary accommodation, they -- linking up with a GP and having continuity of care is really difficult... Test results get lost. People don't know -- you know, there's no coordination ...[they] have to go through this incredibly difficult thing... especially talking about, you know, the exploitation" (Adult NGO)

\section{Accessing Resources}


Responding to the health needs of trafficked people

Participants described how inadequate resources created a barrier to the provision of high-quality health care to trafficked people, highlighting in particular the poor availability of interpreter services and the lack of specialist services to which to refer trafficked people for additional care.

Poor availability of interpretation within healthcare settings was a health system barrier that again intersected with the actions of traffickers to hinder access to care. Traffickers frequently accompanied victims to their medical appointments and offered to translate on their behalf, preventing opportunities for enquiry about and disclosure of abuse.

"I was in the sexual healthcare clinic and I actually saw that kind of situation. This guy was filling in the whole -- you know, the, the referral form for her, and she wasn't getting a look in. And he went up to speak to the desk about her, and he went into the appointment with her" (Adult NGO)

"It tends to be where somebody, a doctor or a nurse... calls us and says, 'I'm concerned because I've normally got a child, or a female, being brought to the surgery and there's somebody - an adult male seems to be there all the time, you know, telling them what to say and all of this'. "' (Adult NGO)

Although professionals reported a preference for face-to-face interpretation, they more often described using telephone-based interpreting services. However, NGOs reported cases in which interpretation was often not available at all, and these most often related to the provision of counselling and psychological therapies. 
Responding to the health needs of trafficked people

"On previous appointments, they would make sure that there was a physical interpreter present. That then stopped, um, and we were under the impression that they were then going to use telephone interpreters. But that hasn't, um, come to be either.... they said it was too expensive, 'We can't keep providing the interpreters', so they're left with nothing." (Adult NGO)

"I would be able to get counselling for people a lot easier than if - if they need interpreters that's where the cut-off is, 'Oh, sorry, we don't provide interpreters,", (Adult NGO)

The poor availability of interpreter services in physical and/or mental healthcare settings was attributed by some NGOs to cost, but logistical problems were also described. In particular, there could be problems accessing an interpreter who spoke the same dialect as the patient, particularly where a female interpreter was preferred because of patients' experiences of sexual abuse and exploitation.

The lack of specialist services to which trafficked people could be referred from primary care was discussed by several participants, with long waiting lists for mental healthcare described as a particular problem.

It doesn't change the waiting times for counselling or anything like that. I don't think [trafficked people] get bumped up the list or anything.... They go on a list for counselling.... I think the GPs seem very limited in what they can do other than referring them on to go on a waiting list...And that again is where, if there are delays and they're just on a waiting list...that can actually be detrimental to the individual." (Adult NGO) 
Responding to the health needs of trafficked people

Finally, participants suggested that trafficked people's limited financial resources could act as a barrier to care, with the prospect of large bills for medical treatment dissuading people from seeking medical care:

"There is the problem that they may be concerned about the cost... because we have big signs everywhere saying that we charge foreign nationals" (Emergency consultant)

"They're allowed access to maternity care, but they often don't go because they know there's a bill for everything, there's a bill for every scan, there's a massive bill for delivery ... and they might be someone who's escaped terrible things abroad or suffered lots of persecution here or abuse and then now hounded with a bill to pay for the baby, it's not quite right" (GP)

Where treatment was successfully accessed, participants stated that many trafficked individuals could not afford the prescription costs:

“No, [the prescriptions] weren't, they weren't free. We had to pay for them. We paid for them as a charity. That was right. They are only free now because she's gone onto employment support allowance, so now they will be free, but, but in the immediacy, we had to pay for that" (Adult NGO)

\section{Knowledge}

Few healthcare professionals reported having received formal training about trafficking, with most describing gaining knowledge 'on the job' during interactions with 
Responding to the health needs of trafficked people

individuals who had been trafficked. This was the case even among the healthcare professionals who were most likely to be in contact with trafficked persons, such as those working in sexual health and maternity services.

'I'm trying to think back to my original training. I don't, we don't get a specific class that's about trafficking. Um, I would say it probably comes up, you know once or twice very briefly in the original training of a midwife." (Maternity professional)

Several healthcare professionals also reported a lack of clarity regarding which organisation to contact when they became aware that an individual had been trafficked.

"I used to be a consultant in [a] hospital and every year we were given a book about that thick, full of all the possible mental health referral pathways, all the charities and all the... I never referred to any of them. ... what I want is one number, to say they have these needs, who do I send them to?" (Emergency Medicine professional)

Many suggested that training and guidance should be available on the identification and appropriate, sensitive treatment of trafficked victims was expressed by many healthcare professionals.

"I think the thing that people want is obviously the signs to look for, but then practically what do you do? That's the most helpful thing for us. Because the theory is very interesting; I think it would be very interesting to go through and understand the law and what the law says about what to do. But then for us working in medical specialities; what do you do practically?" (Sexual health) 
Participants reported that trafficked individuals were most likely to present at Accident and Emergency (A\&E) departments, sexual health clinics, and GP surgeries and suggested that training should be targeted accordingly, as well as being incorporated into training for medical students and junior doctors.

"Every Trust needs to say, 'right, the people who are most likely to be there, to pick up the signs, are again going to be people like A\&E, maternity etc... they're the people to concentrate on.", (Sexual health)

Participants described low levels of knowledge concerning trafficked people's entitlements to care, among both healthcare professionals and trafficked people themselves. Although healthcare professionals reported that they would welcome clearer guidance on trafficked people's entitlements to NHS care, they did not want responsibility for determining individuals' rights to access free care. Determining a patient's rights to treatment on the NHS was thought to be a matter for hospital administrators to deal with. As reported above, trafficked people were described as being mostly unaware of their treatment rights; knowledge of how to access treatment was also limited and was further compounded by complicated care pathways and language barriers.

“Well they won't understand [the NHS], they don't know how to get into it. They probably quite often can't speak English or can't speak English well enough to find out. The NHS is a complete maze, and how do you know which bit to go to?" (Sexual health professional) 
Responding to the health needs of trafficked people

\section{Addressing barriers to care}

Many NGO staff described working extensively to secure trafficked individuals' access to physical and mental healthcare, including proactively assessing likely needs, advocating on behalf of clients, liaising with NHS staff, and arranging transportation to appointments.

"You have to really push for it. You have to be on the phone with a lot of people... but as long as you've got people who are willing to do that, I think eventually they, they, they do, kind of [get help] ... She was literally on the phone consistently to get this lady the care, and she did." (Adult NGO)

Non-NHS staff perceived levels of awareness of the potential signs of trafficking to be low in both NHS healthcare staff and the general public and stressed the need to raise awareness to improve the identification of trafficked persons. In an attempt to address this concern, some participants reported disseminating information to the NHS regarding indicators of trafficking through their organisations.

"I think that the NHS needs to be aware of this because...it's happening quite often. Um, and you know, having gone and done a presentation in a hospital in East London, they've gone, 'Wow, yeah, no, we see that all the time. But we don't know what to do with it. Now we know what to do with it'." (Police)

However, NGO and other non-NHS staff were often limited in their capacity to assist individuals who had been trafficked. This was due to several factors, including a lack of organisational funding and issues relating to data protection. For example, despite NGOs 
Responding to the health needs of trafficked people

playing a key role in advocating for trafficked individuals, arranging interpreters and access to healthcare, NGO staff reported being unable to receive information regarding a trafficked person's treatment and ongoing care needs from the NHS due to data protection and confidentiality issues. In some cases, this limited their ability to best support trafficked people.

"If you're not next of kin, they won't give you any information. And so that's where our battle began again, with the ward clerk...They're the ones that block it all. So, they wouldn't tell us what ward he was on or what was happening. And not only that, they wouldn't tell him, because they didn't have an interpreter." (Adult NGO)

\section{Discussion}

The aim of the study was to explore the experiences of healthcare and non-healthcare professionals in relation to the identification, referral, and provision of care to trafficked people within UK healthcare settings. Four key themes emerged from the data: entitlements to care, accessing resources, healthcare professional's knowledge, and barriers to care. Our results highlight the multiple challenges and barriers that hinder NHS health professionals from identifying and providing care to trafficked people and prevent their referral to often-necessary mental health and social support services. Encouragingly, however, our findings also demonstrate the willingness of healthcare and other professionals to improve care and implement more coordinated system for referral and continuity of care.

An important barrier to trafficked people's access to healthcare - and also to their identification within healthcare settings and referral to other specialist forms of support - was the limited knowledge of NHS staff regarding trafficked people's entitlements to access healthcare without charge. This was compounded by trafficked individuals' restricted knowledge of their rights to care, of how the NHS operates, and, often, that their experiences 
Responding to the health needs of trafficked people

constituted trafficking. Many participants described cases in which trafficked individuals were unable to register with GP surgeries due to lack of identification documents (e.g. proof of address) and may not seek necessary treatment due to concerns about high healthcare costs. Voluntary sector services described how they had to invest already scarce resources into advocating on behalf of their clients in order for them to overcome immigration-related barriers to access necessary medical and psychological treatment. UK legislation specifically exempts individuals who have experienced trafficking from healthcare charges and GPs are not required by law to ascertain the address or immigration status of patients wishing to register with their practice (Burridge, 2017; Murwill, 2018). Awareness of this should be raised in both staff in relevant support organisations and healthcare professionals. Government, NHS managers and health training bodies must also ensure this information reaches those who need to use it in interactions with trafficked people, particularly those in gatekeeping roles (such as GPs' receptionists and other administrators). Confusion amongst these staff regarding the rights and entitlements of trafficked people may contribute to a hostile environment within the NHS for a group who have already been denied basic human rights. Our research also suggests the need for user-friendly materials to be developed and disseminated (e.g. widely available online, via GP surgeries, immigration services, etc.) in order to inform trafficked people about the physical/mental healthcare services that are available to them, their entitlement to healthcare and how to register for it.

Another significant obstacle to the identification, referral, and provision of specialist support to trafficked people was the lack of training and information for NHS staff on the potential indicators of human trafficking and options for onward referral. These findings indicate that healthcare professionals would benefit from training on identifying and responding to human trafficking, as well as clear guidance on referral and support options and entitlement to care. Previous research conducted in the UK found that the majority of staff 
Responding to the health needs of trafficked people

attending mandatory safeguarding events wanted further training and information about human trafficking (Ross et al., 2015). Training should be targeted towards staff who are most likely to come into contact with trafficked persons, such as staff in primary care, sexual health, emergency medicine, maternity care, and mental health (Ross et al., 2015; Westwood et al., 2016). Training should include easy-to-access and up-to-date information concerning relevant resources and specialist services for trafficked people. It would also be beneficial for staff to receive clear guidance to assist them in recognising situations where trafficked people are accompanied by their trafficker and advice on what action to take; guidance in this regard could draw upon best practice when responding to suspected cases of domestic violence or child abuse (Carter, Bannon, Limbert, Docherty, \& Barlow, 2006).

Professionals also described a lack of interpretation services as well as the inadequate provision of specialist services to meet the needs of people who have experienced severe trauma and abuse. Poor availability of interpretation services may hinder the identification of trafficked people as traffickers may pose as 'friends' or 'family members' and offer to translate for the victim or speak on their behalf at appointments (Patel, Ahn, \& Burke, 2010). Problems with accessing interpretation services were reportedly due to cost, as well as logistical problems (e.g. unable to access interpretation who spoke the same dialect; unavailability of female interpreters in cases of sexual abuse, etc.). These findings highlight a need for increased provision and accessibility of interpreter services across healthcare settings, which has been found to result in more thorough clinical history taking and improve patient understanding of health-related information (Jacobs et al., 2001). Particularly in mental health care, commissioners must ensure sufficient funds are available for interpreter services throughout patient treatment. Moreover, given the particularly sensitive nature of assessments with trafficked people, specialist training for interpreters working with trafficked individuals may also be beneficial (Hemmings et al., 2016). 
Responding to the health needs of trafficked people

Poor continuity of care was frequently reported due to patient relocation linked to the provision of various social and financial services. Our previous research based on analyses of medical records found that the relocation of trafficked people within the UK as part of immigration proceedings interrupts the provision of necessary physical and mental healthcare (Domoney et al., 2015). Trafficked people with physical or mental health needs, or who are pregnant or have recently given birth should not be subject to dispersal or otherwise relocated (unless remaining in a given location poses a risk to their safety) due to the adverse impact of relocation on their ongoing care (Bick, Howard, Oram, \& Zimmerman, 2017). Research suggests that the majority of trafficked people in contact with shelter services are likely to present with this profile of needs (Oram et al., 2016), therefore this should be considered by healthcare and social services when creating patients' care plans. NGOs' support to trafficked people was also reportedly hindered due to issues with data protection, with NGOs often unable to access information about patient treatment and care needs from the NHS - meaning NGOs' ability to advocate and arrange access to treatment was limited. A recent systematic review found good coordination across health providers and voluntary organisations is key to ensure comprehensive high-quality care is delivered to trafficked people (Hemmings et al., 2016). The results of this study indicate that improved communication between agencies and routinely seeking patient consent for the secure sharing of their information across agencies (e.g. NGOs and the NHS) may improve the provision of care to trafficked people. Secure data sharing of patient information is an undoubtedly complex process and additional research is needed to explore how to best improve interagency collaboration in cases of trafficking and develop effective procedures.

\section{Strengths and limitations}

Our study had several strengths. Rich data were collected from participants in both the healthcare and non-healthcare sectors, including from the public and third sectors. A range of 
Responding to the health needs of trafficked people

clinical specialities and geographical areas were represented. However, some potential limitations should be noted. First, although all participants appeared to speak candidly about their experiences during their interviews, it is impossible to eradicate the influence of researcher and participant characteristics (e.g., social desirability) on the data collected. Second, we did not include trafficked people as participants in this study nor enquire about their experiences of accessing healthcare; however, this was the focus of a separate study within the same programme of research and was reported recently elsewhere (Westwood et al., 2016). Third, because we sampled participants with experience or expertise in responding to human trafficking, the views expressed are unlikely to be representative of the wider NHS. For example, the high level of support expressed for human trafficking training may not be more widely held. Other research has, however, demonstrated a high level of interest in human trafficking training among health professionals attending mandatory safeguarding training across ten healthcare Trusts in England (Ross et al., 2015). Finally, some professional groups, such as mental health and children's NGOs, were less well represented in the present study and their views should be further incorporated in future studies.

\section{Conclusion}

The study provides some of the first evidence of healthcare professionals' experiences of identifying, referring, and providing care to trafficked people and the experiences of other professionals whose work with trafficked people brings them into contact with the health service. The findings highlight the need for additional training for the staff working in clinical settings most likely to be accessed by trafficked people to improve identification and response to trafficking, as well as guidance regarding the specialist support available and entitlements to care. This research also illustrates the need for greater collaboration across services to deliver ongoing care which may ultimately improve patient wellbeing. Ultimately, however, 
Responding to the health needs of trafficked people

improving the recognition and care of trafficked people within health services is likely to require government action to ensure trafficked people are not unjustifiably denied medical care. 


\section{References}

Abas, M., Ostrovschi, N. V., Prince, M., Gorceag, V. I., Trigub, C., \& Oram, S. (2013). Risk factors for mental disorders in women survivors of human trafficking: A historical cohort study. BMC Psychiatry. http://doi.org/10.1186/1471-244X-13-204

Baldwin, S. B., Eisenman, D. P., Sayles, J. N., Ryan, G., \& Chuang, K. S. (2011). Identification of human trafficking victims in health care settings. Health Hum Rights.

Bick, D., Howard, L. M., Oram, S., \& Zimmerman, C. (2017). Maternity care for trafficked women: Survivor experiences and clinicians' perspectives in the United Kingdom's National Health Service. PLOS ONE, 12(11), e0187856. http://doi.org/10.1371/journal.pone.0187856

Braun, V., \& Clarke, V. (2006). Using thematic analysis in psychology. Qualitative Research in Psychology, 3(1), 77-101.

Burridge, S. (2017). Three forms of identification and a letter from God. BMJ (Clinical Research Ed.), 359, j4669. http://doi.org/10.1136/BMJ.J4669

Carter, Y. H., Bannon, M. J., Limbert, C., Docherty, A., \& Barlow, J. (2006). Improving child protection: a systematic review of training and procedural interventions. Archives of Disease in Childhood, 91(9), 740-3. http://doi.org/10.1136/adc.2005.092007

Domoney, J., Howard, L. M., Abas, M., Broadbent, M., \& Oram, S. (2015). Mental health service responses to human trafficking: A qualitative study of professionals' experiences of providing care. BMC Psychiatry. http://doi.org/10.1186/s12888-015-0679-3

Hemmings, S., Jakobowitz, S., Abas, M., Bick, D., Howard, L. M., Stanley, N., ... Oram, S. (2016). Responding to the health needs of survivors of human trafficking: a systematic review. BMC Health Services Research, 16(1), 320. http://doi.org/10.1186/s12913-016$1538-8$

International Labour Organization (2017). Methodology of the global estimates of modern 
Responding to the health needs of trafficked people

slavery: Forced labour and forced marriage. Geneva.

Jacobs, E. A., Lauderdale, D. S., Meltzer, D., Shorey, J. M., Levinson, W., \& Thisted, R. A. (2001). Impact of interpreter services on delivery of health care to limited-Englishproficient patients. Journal of General Internal Medicine, 16(7), 468-474. http://doi.org/10.1046/j.1525-1497.2001.016007468.x

Kiss, L., Pocock, N. S., Naisanguansri, V., Suos, S., Dickson, B., Thuy, D., ... Zimmerman, C. (2015). Health of men, women, and children in post-trafficking services in Cambodia, Thailand, and Vietnam: an observational cross-sectional study. The Lancet Global Health, 3(3), e154-e161. http://doi.org/10.1016/S2214-109X(15)70016-1

Murwill, P. (2018). A world without barriers to healthcare. Practice Management, 28(1), 12 15. http://doi.org/10.12968/prma.2018.28.1.12

Oram, S., Abas, M., Bick, D., Boyle, A., French, R., Jakobowitz, S., ... Zimmerman, C. (2016). Human trafficking and health: A survey of male and female survivors in England. American Journal of Public Health, 1-6. http://doi.org/10.2105/AJPH.2016.303095

Oram, S., Khondoker, M., Abas, M., Broadbent, M., \& Howard, L. M. (2015). Characteristics of trafficked adults and children with severe mental illness: A historical cohort study. The Lancet Psychiatry, 2(12), 1084-1091. http://doi.org/10.1016/S2215-0366(15)002904

Oram, S., Ostrovschi, N. V, Gorceag, V. I., Hotineanu, M. A., Gorceag, L., Trigub, C., \& Abas, M. (2012). Physical health symptoms reported by trafficked women receiving post-trafficking support in Moldova: prevalence, severity and associated factors. $B M C$ Women's Health, 12(1), 20. http://doi.org/10.1186/1472-6874-12-20

Oram, S., Stöckl, H., Busza, J., Howard, L. M., \& Zimmerman, C. (2012). Prevalence and risk of violence and the physical, mental, and sexual health problems associated with 
Responding to the health needs of trafficked people

human trafficking: Systematic review. PLoS Medicine, 9(5).

http://doi.org/10.1371/journal.pmed.1001224

Ottisova, L., Hemmings, S., Howard, L. M., Zimmerman, C., \& Oram, S. (2016). Prevalence and risk of violence and the mental, physical and sexual health problems associated with human trafficking: an updated systematic review. Epidemiology and Psychiatric Sciences, 25(04), 317-341. http://doi.org/10.1017/S2045796016000135

Patel, R. B., Ahn, R., \& Burke, T. F. (2010). Human trafficking in the emergency department. The Western Journal of Emergency Medicine, 11(5), 402-4. Retrieved from http://www.ncbi.nlm.nih.gov/pubmed/21293753

Ross, C., Dimitrova, S., Howard, L. M., Dewey, M., Zimmerman, C., \& Oram, S. (2015). Human trafficking and health: A cross-sectional survey of NHS professionals' contact with victims of human trafficking. BMJ Open. http://doi.org/10.1136/bmjopen-2015008682

Turner-Moss, E., Zimmerman, C., Howard, L. M., \& Oram, S. (2014). Labour exploitation and health: A case series of men and women seeking post-trafficking services. Journal of Immigrant and Minority Health. http://doi.org/10.1007/s10903-013-9832-6

Viergever, R. F., West, H., Borland, R., \& Zimmerman, C. (2015). Health Care Providers and Human Trafficking: What do They Know, What do They Need to Know? Findings from the Middle East, the Caribbean, and Central America. Frontiers in Public Health. http://doi.org/10.3389/fpubh.2015.00006

Westwood, J., Howard, L. M., Stanley, N., Zimmerman, C., Gerada, C., \& Oram, S. (2016). Access to, and experiences of, healthcare services by trafficked people: Findings from a mixed-methods study in England. British Journal of General Practice. http://doi.org/10.3399/bjgp16X687073

Williams, T. P., Alpert, E. J., Ahn, R., Cafferty, E., Konstantopoulos, W. M., Wolferstan, N., 
Responding to the health needs of trafficked people

... Burke, T. F. (2010). Sex trafficking and health care in metro manila: Identifying social determinants to inform an effective health system response. Health and Human Rights. http://doi.org/10.2307/healhumarigh.12.2.135

Zimmerman, C., Hossain, M., \& Watts, C. (2011). Human trafficking and health: A conceptual model to inform policy, intervention and research. Social Science and Medicine. http://doi.org/10.1016/j.socscimed.2011.05.028

Zimmerman, C., Hossain, M., Yun, K., Gajdadziev, V., Guzun, N., Tchomarova, M., ... Watts, C. (2008). The health of trafficked women: A survey of women entering posttrafficking services in Europe. American Journal of Public Health. http://doi.org/10.2105/AJPH.2006.108357

Zimmerman, C., Lieder, F., Goodman, N. D., Huys, Q. J. M., Tsutsumi, A., Izutsu, T., ... Marui, E. (2013). The Health Risks and Consequences of Trafficking in Women and Adolescents Trafficking in Women and Adolescents: Findings from a European Study. Proceedings of the 35th Annual Conference of the Cognitive Science Society. http://doi.org/10.1016/j.socscimed.2007.12.025 
Responding to the health needs of trafficked people

Table 1

Interview topics for healthcare and non-healthcare professionals

\begin{tabular}{|l|}
\hline \multicolumn{1}{|c|}{ Interview topics } \\
\hline Knowledge and training regarding trafficking issues. \\
\hline Experiences providing care to individuals they knew or suspected had been trafficked. \\
\hline Experiences working with (and making referrals to) external agencies. \\
identifying victims; providing care to victims; referring victims onward and collaborating \\
\hline Beliefs about potential indicators that an individual may have been trafficked. \\
\hline Experience referring within the NHS (healthcare professionals only). \\
\hline Their experience making referrals to or receiving referrals from the NHS (non-healthcare \\
professionals only).
\end{tabular}


Responding to the health needs of trafficked people

Table 2. Interviewee professions

\begin{tabular}{|c|c|}
\hline Profession & $N$ \\
\hline \multicolumn{2}{|l|}{ NHS employees } \\
\hline Maternity & 5 \\
\hline GP & 5 \\
\hline Sexual health & 3 \\
\hline Forensics and sexual assault & 3 \\
\hline \multicolumn{2}{|l|}{ referral centres } \\
\hline Paediatrics & 2 \\
\hline Psychiatry & 2 \\
\hline Other & 3 \\
\hline \multicolumn{2}{|l|}{ Non-NHS employees } \\
\hline Civil service & 7 \\
\hline NGO (care of adults) & 8 \\
\hline NGO (care of children) & 2 \\
\hline Police & 6 \\
\hline UKHTC & 4 \\
\hline
\end{tabular}

Note: NHS $=$ National Health Service. GP $=$ General Practitioner. NGO $=$ non-government organisations. UKHTC $=$ United Kingdom Human Trafficking Centre (a police-led organisation tasked with the identification of trafficked people). 